\title{
Characterisation of the rat oesophagus epithelium antigens defined by the so-called 'antikeratin antibodies', specific for rheumatoid arthritis ${ }^{\star}$
}

Elisabeth Girbal and Mireille Sebbag, † Véronique Gomès-Daudrix, Michel Simon, Christian Vincent, Guy Serre

\begin{abstract}
Objectives-An attempt was made to characterise the antigens recognised by serum IgG antibodies directed to the stratum corneum of rat oesophagus epithelium, the so-called 'antikeratin antibodies', which were shown to be highly specific for rheumatoid arthritis (RA) and thus to have an actual diagnostic value. Methods-Immunoblotting was performed with RA serum samples on different extracts of rat oesophagus epithelium separated by various monodimensional and two dimensional electrophoreses.
\end{abstract}

Results-Three low-salt-soluble antigens sensitive to proteinase $K$ and, therefore, of protein nature were identified. Two proteins, with apparent molecular masses of 210 and 120-90 kilodaltons, shared isoelectric points ranging from 5.8 to $8 \cdot 5$; the third protein exhibited isoelectric points from $4 \cdot 5$ to $7 \cdot 2$ while its molecular mass ranged from 130 to 60 kilodaltons. Immunoadsorption of RA serum samples onto cytokeratins extracted from the stratum corneum of rat oesophagus epithelium did not change their immunoreactivity towards the three antigenic proteins. Widely used deglycosylation and dephosphorylation methods failed to modify either the electrophoretic migration of the proteins or their immunoreactivity with RA serum samples.

Conclusion-The so-called 'antikeratin antibodies' do not react with cytokeratins. They specifically recognise three late epithelial differentiation proteins which had not been previously described. These proteins may be related to (pro)filaggrin.

(Ann Rheum Dis 1993; 52: 749-757)

Serum samples from patients with rheumatoid arthritis (RA) show a wide variety of circulating autoantibodies, such as rheumatoid factors, ${ }^{12}$ antinuclear antibodies, ${ }^{34}$ and autoantibodies to tissue antigens, such as perinuclear

*This work was presented in part at the International Conference on Cellular and Molecular Aspects of SelfReactivity and Autoimmune Diseases, Taormina (Italy), 7-12 June 1992, and at the International Congress of Immunology, Budapest (Hungary), 24-29 August 1992.

This work results from an equal contribution by the first two authors. granules ${ }^{5}$ or collagen. ${ }^{7-9}$ This study deals with the circulating IgG antibodies, described in 1979 by Young et al, ${ }^{10}$ which label the stratum corneum (SC) of rat oesophagus epithelium when tested by indirect immunofluorescence (IIF). Over the past few years numerous authors have shown that these antibodies are specific for RA and thus useful for its diagnosis. ${ }^{11-19}$ Previously we used semiquantitative IIF, on a large series of serum samples, to determine the diagnostic specificity and sensitivity of detection of these antibodies (99\% and $41.5 \%$, respectively). ${ }^{19}$ Their presence in the RA.serum samples was found to be independent of age, sex, and disease duration but to be related significantly to disease severity and activity (see 18 for cross references). Moreover, they were recently shown to be present in early RA and even before the onset of clinical symptoms. ${ }^{2021}$ Today, these antibodies are the most reliable diagnostic and prognostic serological marker for RA. ${ }^{18}$ Lastly, they have also been detected in rheumatoid synovial fluids ${ }^{1422}{ }^{23}$ with higher concentrations than in the related serum samples, ${ }^{23}$ suggesting that they might be locally synthesised and possibly play a part in the pathogenesis of RA synovitis.

Probably because cytokeratins constitute the major proteins of the SC, these antibodies, which produce a linear laminated labelling restricted to this epithelial layer only, were called 'antikeratin' antibodies without any previous biochemical characterisation of the antigens. Confirming data obtained on short series by other authors, ${ }^{1022}{ }^{24}$ we have shown that these antibodies also label the SC of human epidermis and are thus genuine autoantibodies. ${ }^{17}$

On the other hand, naturally occurring IgM and IgG autoantibodies directed to epidermal cytokeratins have been described in all normal human serum samples, as well as in serum from patients with various diseases, including RA. ${ }^{17}{ }^{25}{ }^{26}$ The simultaneous investigation, on a large series of RA serum samples, of these natural IgG autoantibodies to epidermal cytokeratins and of the antibodies to SC specific for RA, allowed us to show that they were directed to different epitopes, probably borne by different molecules. ${ }^{17} 19$

In this study we present the first isolation, physicochemical and biochemical characterisation of the rat oesophagus epithelial antigens recognised by the antibodies to SC specific for RA, the so-called 'antikeratin antibodies'.

France. 


\section{Materials and methods}

HUMAN SERUM SAMPLES

Serum samples were obtained from healthy donors and from patients with RA according to the clinical, radiographic, and biological criteria of the American Rheumatism Association. ${ }^{27}$

The samples were assayed by semiquantitative IIF for the presence of IgG antibodies to the SC of rat oesophagus epithelium, as previously described. ${ }^{18}$ Briefly, the titre-like value was estimated by eye on a semiquantitative scale from 0 to $4(0.25$ unit steps) independently by two readers who had not been informed of the clinical context. The results were summed giving titre-like values ranging from 0 to 8 .

\section{PREPARATION OF ANTIGENS FROM RAT}

OESOPHAGUS EPITHELIUM

Specimens of frozen oesophagus from 6-weekold male Wistar rats were obtained from IffaCredo (Lyon, France) and stored at $-80^{\circ} \mathrm{C}$ until use. After removing the outside muscularis by gentle scraping the oesophagus was incubated at $55^{\circ} \mathrm{C}$ for five minutes in phosphate buffered saline, $\mathrm{pH} 7 \cdot 4$, containing $5 \mathrm{mM}$ EDTA and $0.4 \mathrm{mM}$ phenylmethylsulphonyl fluoride, then chilled for five minutes in the same ice cold buffer without EDTA. The epithelium was mechanically separated from the underlying connective tissue then pooled and ground at $4^{\circ} \mathrm{C}$ with a tissue homogeniser in a low salt, $40 \mathrm{mM}$ TRIS-HCl buffer, $\mathrm{pH} 7 \cdot 5$ containing $150 \mathrm{mM} \mathrm{NaCl}, 10 \mathrm{mM}$ EDTA, $0.1 \%$ sodium azide, and $0.1 \mathrm{mM}$ phenylmethylsulphonyl fluoride $(0.25 \mathrm{ml}$ buffer per epithelium). The insoluble material was removed by centrifugation at $25000 \mathrm{~g}$ for 15 minutes and the supernatant stored at $-30^{\circ} \mathrm{C}$ The protein concentration of the epithelial extract was estimated using chicken egg albumin as standard by either absorbance measurement at $280 \mathrm{~nm}$ or by the BioRad Protein Assay (Bio-Rad Laboratories, Richmond, CA).

PREPARATION OF CYTOKERATINS FROM RAT OESOPHAGUS EPITHELIUM

Sequential extraction of epithelial proteins was performed according to Sun and Green. ${ }^{28}$ The epithelial sheets were extracted three times in $20 \mathrm{mM}$ TRIS-HCl, $\mathrm{pH} 7 \cdot 4$, then the insoluble pellet was extracted three times with the same buffer containing $8 \mathrm{M}$ urea (solubilisation of the cytokeratins from the viable layers). Lastly, the pellet was extracted three times with the same buffer containing $8 \mathrm{M}$ urea plus $0 \cdot 1 \mathrm{M}$ $\beta$-mercaptoethanol (solubilisation of the cross linked cytokeratins from the SC). The TRIS-urea- $\beta$-mercaptoethanol-soluble fractions were pooled, dialysed against water, and lyophilised.

ELECTROPHORESIS

Polyacrylamide gel electrophoresis (PAGE) was performed with a PhastSystem (Pharmacia-
LKB, Uppsala, Sweden) using precast gels and following the procedures suggested by the manufacturer. Sodium dodecyl sulphate (SDS)-PAGE was performed either with $7.5 \%$ homogeneous or with $8-25 \%$ gradient PhastGels, non-denaturing PAGE (nativePAGE) with $8-25 \%$ gradient PhastGels, and isoelectrofocusing (IEF) using PhastGels with ampholytes generating either a 3-9 or a $5-8 \mathrm{pH}$ gradient. The high molecular weight standard protein kit from Biorad was used in SDSPAGE and the broad range isoelectric calibration kit from Pharmacia was used for IEF. For native-PAGE the following proteins (Pharmacia-LKB) were used as markers: horse spleen ferritin (440 kilodaltons), beef liver catalase (232 kilodaltons), beef heart lactate dehydrogenase (140 kilodaltons), and bovine serum albumin (67 kilodaltons). Epithelial proteins were concentrated by lyophilisation or precipitation either with four volumes of ethanol for 30 minutes at $-30^{\circ} \mathrm{C}$ or with $10 \%$ trichloroacetic acid for 15 minutes at $0^{\circ} \mathrm{C}$. For SDS-PAGE the precipitate was dissolved in $10 \mathrm{mM}$ TRIS-HCl, $\mathrm{pH} 7 \cdot 4,2 \%$ SDS, $0.01 \%$ bromophenol blue, and $1 \% \quad \beta$-mercaptoethanol (SDS sample buffer), and boiled for five minutes. The lyophilised SC cytokeratins were dissolved and boiled in $20 \mathrm{mM}$ TRIS$\mathrm{HCl}, \mathrm{pH} 7 \cdot 4$, containing $6 \mathrm{M}$ urea, $4 \%$ SDS, $1 \% \beta$-mercaptoethanol, and $0.01 \%$ bromophenol blue. For native-PAGE and IEF the precipitate was dissolved in distilled water with $0.01 \%$ bromophenol blue. For two dimensional electrophoresis one lane of the first dimensional gel (IEF or native-PAGE) was equilibrated either in $112 \mathrm{mM}$ TRIS- $\mathrm{HCl}, \mathrm{pH}$ 6.5 , containing $112 \mathrm{mM}$ acetic acid, $2 \cdot 5 \%$ SDS, $1 \% \quad \beta$-mercaptoethanol, and $0.01 \%$ bromophenol blue, when the second dimension was SDS-PAGE, or in $200 \mathrm{mM}$ TRIS$\mathrm{HCl}, \mathrm{pH} 8.8$, with $0.01 \%$ bromophenol blue, when the second dimension was native-PAGE. Then, the lane was placed horizontally onto the second dimension stacking gel and electrophoresis was run as above.

IMMUNOBLOTTING

After electrophoretic separation the epithelial extracts were electrotransferred to nitrocellulose membranes (Bio-Rad) according to the method of Towbin et al. ${ }^{29}$ The membranes were blocked for 30 minutes with $10 \mathrm{mM}$ TRIS- $\mathrm{HCl}, \mathrm{pH} 8 \cdot 0,150 \mathrm{mM} \mathrm{NaCl}$, containing $0.05 \%$ Tween-20 and $0.5 \%$ skimmed dry milk (working buffer). Then the membranes were incubated overnight at $4^{\circ} \mathrm{C}$ in working buffer containing human serum samples diluted to 1:100. After three washing steps in working buffer the membranes were treated for 90 minutes at room temperature with peroxidase conjugated goat antibodies to the human $\gamma$ heavy chain of immunoglobulins (Southern Biotech Inc, Birmingham, AL) diluted 1:400 in working buffer. After one wash in working buffer and two washes in $10 \mathrm{mM}$ TRIS- $\mathrm{HCl}$, $\mathrm{pH} 8 \cdot 0,150 \mathrm{mM} \mathrm{NaCl}$, the colour reaction was developed by incubation with peroxidase substrates: $0.5 \mathrm{mg} / \mathrm{ml}$ 4-chloro-1-naphthol 
(Bio-Rad) in $0.025 \%(\mathrm{v} / \mathrm{v})$ hydrogen peroxide.

In some cases the staining intensity of the strips was estimated semiquantitatively exactly as described above for IIF reactivity and a titrelike value was attributed to each serum within a scale from 0 to 8 with steps of $0 \cdot 25$.

\section{IMMUNOADSORPTION}

Nitrocellulose membranes were electroblotted either with the low-salt-soluble epithelial extract separated by native-PAGE or with the TRIS-urea- $\beta$-mercaptoethanol-soluble SC cytokeratins separated by SDS-PAGE. An RA serum, diluted 1:200 in working buffer, was immunoadsorbed by five successive incubations at $4^{\circ} \mathrm{C}$ (three times for three hours then twice for 12 hours) with the two types of membranes previously saturated. Unblotted nitrocellulose membranes were used as control.

\section{CHROMATOGRAPHIC TECHNIQUES}

Chromatography was performed on prepacked columns using an FPLC System (PharmaciaLKB). The low-salt-soluble epithelial extract was first applied to a gel filtration column (Superose $12,30 \times 1.4 \mathrm{~cm}$ ) and the proteins were eluted in $50 \mathrm{mM}$ sodium phosphate, pH $7 \cdot 2,150 \mathrm{mM} \mathrm{NaCl}$, at $0.3 \mathrm{ml} / \mathrm{min}$. Each collected fraction was analysed by nativePAGE and immunoblotting. The fractions of interest were pooled and $1.7 \mathrm{M}$ ammonium sulphate was added for further hydrophobic interaction chromatography on a phenylSuperose column $(5 \times 0.5 \mathrm{~cm})$ previously equilibrated with $50 \mathrm{mM}$ sodium phosphate, $\mathrm{pH} 7 \cdot 2$, containing $1 \cdot 7 \mathrm{M}$ ammonium sulphate. Elution was performed at $0.5 \mathrm{ml} / \mathrm{min}$ by decreasing the ammonium sulphate concentration in the equilibrium buffer; it was led stepwise to $0.765 \mathrm{M}$ then progressively decreased to $0.36 \mathrm{M}$ before final washing with sodium phosphate buffer. Absorbance was monitored at $280 \mathrm{~nm}$ and the fractions were concentrated, then analysed by native-PAGE and immunoblotting.

ENZYMATIC AND CHEMICAL TREATMENT OF THE ANTIGENIC EPITHELIAL EXTRACT Proteinase $K$ digestion

The low-salt-soluble epithelial extract $(6.5 \mathrm{mg} / \mathrm{ml})$ was precipitated with ethanol and solubilised, concentrated 20 -fold, in $50 \mathrm{mM}$ TRIS- $\mathrm{HCl}, \mathrm{pH} 8.0$ and $5 \mathrm{mM} \mathrm{CaCl}_{2}$. Aliquots were incubated at $37^{\circ} \mathrm{C}$ for one hour with either water or an aqueous solution of Tritirachium album proteinase $\mathrm{K}$ (Boehringer Mannheim, Germany) at a final concentration of $2 \mathrm{U} / \mathrm{ml}$.

\section{Alkaline $\beta$ elimination}

Several conditions of alkaline $\beta$ elimination of the $O$-linked carbohydrates were tested using $\mathrm{NaOH}$ concentrations from 0.1 to $0.5 \mathrm{~mol} / 1$ applied during times varying from 0.5 to 20 hours at 20 or $37^{\circ} \mathrm{C} .{ }^{30}$ The lyophilised epithelial extract was incubated either with $\mathrm{NaOH}$ or in water. After neutralisation the samples were precipitated with trichloroacetic acid.

\section{$N$-glycanase treatment}

The lyophilised epithelial extract was treated with $N$-glycanase (Genzyme, Boston, MA); samples $(8 \mathrm{mg} / \mathrm{ml}$ final concentration) were boiled for five minutes in one volume of $2 \%$ SDS, $50 \mathrm{mM} \beta$-mercaptoethanol, then incubated for 24 hours at $37^{\circ} \mathrm{C}$ after adding two volumes of a $250 \mathrm{mM}$ potassium phosphate buffer, $\mathrm{pH} 8 \cdot 0$, containing $15 \mathrm{mM}$ 1,10-o-phenanthroline, $15 \%(\mathrm{v} / \mathrm{v})$ methanol, and $1.9 \%(\mathrm{v} / \mathrm{v})$ Nonidet $\mathrm{P}-40$ with or without $\mathrm{N}$-glycanase at a final concentration of $0.03 \mathrm{U} / \mathrm{ml}$. The samples were concentrated by trichloroacetic acid precipitation. The $N$-glycanase activity was tested on fetuin from fetal calf serum (Sigma, St Louis, MO) using the same conditions. ${ }^{31}$

\section{Neuraminidase treatment}

The lyophilised epithelial extract $(2 \mathrm{mg})$ was incubated for 120 minutes at $37^{\circ} \mathrm{C}$ with or without neuraminidase from Vibrio cholerae (Boehringer Mannheim) at a final concentration of $1 \mathrm{U} / \mathrm{ml}$ in $200 \mu \mathrm{l}$ of $50 \mathrm{mM}$ sodium acetate buffer, $\mathrm{pH} 5 \cdot 5$, containing $150 \mathrm{mM} \mathrm{NaCl}, 9 \mathrm{mM} \mathrm{CaCl}, 0.05 \%$ sodium azide, and $25 \mathrm{mg} / \mathrm{ml}$ human serum albumin. Then the samples were precipitated with ethanol. Human $\alpha_{1}$ acid glycoprotein (Sigma), digested in the same conditions, allowed the neuraminidase activity to be checked. ${ }^{32}$

\section{Alkaline phosphatase treatment}

The paradoxically acid conditions determined by Harada et $a l^{33}$ for the phosphoprotein phosphatase activity of the bovine intestinal alkaline phosphatase were used. The lyophilised epithelial extract $(1.5 \mathrm{mg})$ was incubated for two hours at $37^{\circ} \mathrm{C}$ with or without calf intestine alkaline phosphatase (Boehringer Mannheim) at a final concentration of 0.224 $\mathrm{U} / \mu \mathrm{g}$ of treated material in $750 \mu \mathrm{l}$ of $25 \mathrm{mM}$ sodium acetate buffer, $\mathrm{pH} 5 \cdot 6$, containing $280 \mathrm{mM} \mathrm{NaCl}, 3 \mathrm{mM} \mathrm{MgCl}_{2}, 9.5 \mu \mathrm{M}$ $\mathrm{ZnCl}_{2}$, and $2.8 \mathrm{mM}$ triethanolamine. Then the samples were dialysed and lyophilised. The protein phosphatase activity was checked on hen yolk phosvitin (Sigma) and the method of Cutting and Roth for specific staining of phosphoproteins after SDS$\mathrm{PAGE}^{34}$ was used to evaluate dephosphorylation.

After digestion with enzymes or chemical treatment the samples of epithelial extract were analysed by monodimensional or two dimensional electrophoresis and by immunoblotting with RA serum samples, as described above.

STATISTICAL ANALYSES

Correlations were sought using Spearman rank correlation coefficients. 


\section{Results}

IDENTIFICATION OF THE SC ANTIGENS

Various conditions for extraction of the rat oesophagus epithelium antigens were compared using several low salt buffers with or without addition of denaturing or reducing agents (urea, SDS, $\beta$-mercaptoethanol) and detergents (Nonidet P-40, Triton X-100). No significant difference in the efficiency of antigen extraction was found between the various conditions; urea and detergents only inducing the additional solubilisation of nonantigenic epithelial proteins. Thus a simple low ionic strength buffer was used for the immunoblotting analysis of a series of RA serum samples (fig 1). After separation of the extract by SDS-PAGE, 16 of the 18 RA serum samples chosen with IIF titre-like values for antibodies to $\mathrm{SC}$ ranging from 0.25 to 7 (scale 0 to 8 ) were immunoreactive with a smear of 90-130 kilodaltons apparent molecular mass, and 14 of the 16 serum samples also reacted with a sharper band of about 210 kilodaltons. With the high titred serum samples, the reactivity spread between these two regions and on down to 60 kilodaltons. After separation of the extract by non-denaturing electrophoresis (native-PAGE), the RA serum samples with high titre-like values of antibodies to SC recognised three antigenic components: the first migrated like the 440 kilodalton protein marker and was referred to as the $\mathrm{A}$ antigen, a second migrated like the 232 kilodalton marker (B antigen), and a third migrated between the 140 and 67 kilodalton markers (C antigen). The major reactivity was directed to the $B$ antigen with weaker staining of the A antigen. All serum samples with an IIF titrelike value greater than 2.00 recognised the $A$ antigen and all those with an IIF titre-like value greater than 0.25 recognised the $B$ antigen. The $\mathrm{C}$ antigen was detected by some RA serum

A

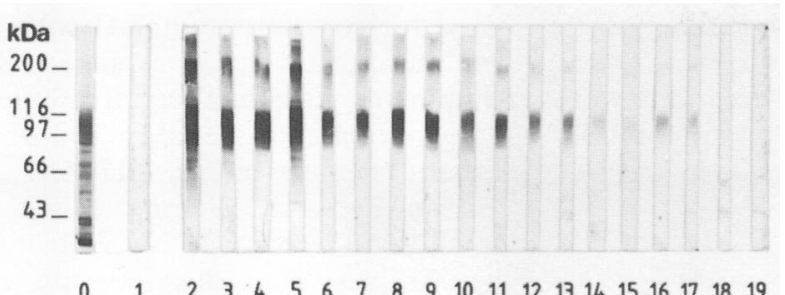

B

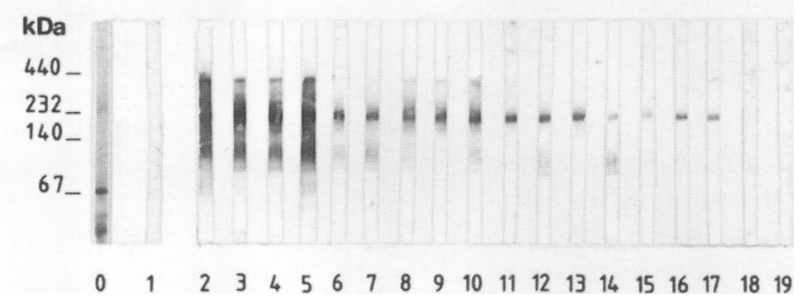

Figure 1 Immunoblotting analysis of low salt extract of oesophagus epithelia with $R A$ serum samples. A rat oesophagus epithelium homogenate was obtained in a low salt buffer. The soluble fraction was precipitated by ethanol and solubilised either in sodium dodecyl sulphate (SDS) sample buffer then separated by 7.5\% SDS-PAGE (A),or in water then separated by 8-25\% native-PAGE (B). Electroblotting was performed on nitrocellulose membranes which were cut into vertical strips and incubated with human serum samples according to 'Materials and methods'. Lane $0=$ Coomassie blue staining of the related gel. lane $1=$ control strip incubated with peroxidase labelled antihuman IgG; lanes 2-19=immunodetection using $R A$ serum samples with decreasing IIF titre-like values ofantibodies to $S C$ ranging from 7 to $0 \cdot 25$. Migration of protein markers in kilodaltons $(k D a)$ is shown on the left. samples with IIF titre-like values higher than 0.75 and by all RA serum samples with IIF titre-like values higher than $3 \cdot 00$. The staining intensity of the $\mathrm{C}$ antigen was not always related to that of the two other antigens.

Despite the difference in the patterns of reactivity obtained after SDS-PAGE and after native-PAGE separation of the extract, both the immunoblotting analyses showed a striking specificity for RA, as healthy donor serum samples showed either no or weak reactivity with the antigenic components (not shown). For the whole series of RA serum samples a highly significant correlation was observed between the IIF titre-like value of antibodies to SC and the staining intensity of the blots semiquantitatively estimated $\left(\mathrm{r}=0.96, \mathrm{p}<10^{-6}\right.$ : antigens separated by SDS-PAGE; $\mathrm{r}=0.94, \mathrm{p}<10^{-6}$ : antigens separated by native-PAGE). In the same way, the titre-like values of the serum samples in the two immunoblotting assays were highly significantly correlated $\left(r=0.98, \mathrm{p}<10^{-6}\right)$.

Although the solubility and the apparent molecular masses of the antigens specific for RA were different from those of the rat oesophagus epithelium cytokeratins, we performed immunoadsorption experiments to assess the antigenic independence of the two types of epithelial molecules. Certain RA serum samples, highly reactive with the three, A, B, and C, epithelial antigens and also reactive with the rat oesophagus SC cytokeratins when assayed by immunoblotting, were immunoadsorbed either onto epithelial antigens or onto cytokeratins, then analysed by immunoblotting. The immunoadsorption of one serum onto SC cytokeratins (fig 2) did not change its reactivity to antigen $\mathrm{A}, \mathrm{B}$, or $\mathrm{C}$, whereas it completely abolished the reactivity to the cytokeratins. Immunoadsorption of the serum onto antigens $\mathrm{A}, \mathrm{B}$, and $\mathrm{C}$ did not modify its reactivity to the cytokeratins, whereas it substantially reduced its reactivity to all three antigens. When unblotted nitrocellulose sheets were used as immunosorbent the reactivity of the serum samples remained largely unmodified.

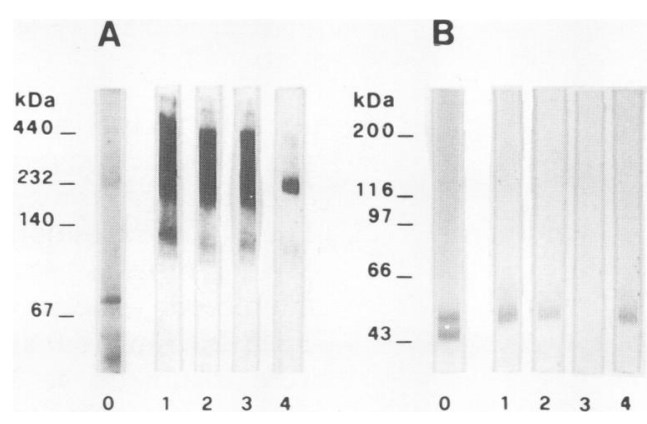

Figure 2 Immunoblotting analysis using an $R A$ serum previously immunoadsorbed either on stratum corneum (SC) cytokeratins or cn the low-salt-soluble epithelial antigens. The low-salt-soluble antigens, separated by native-PAGE $(A)$, and SC cytokeratins, extracted with TRIS-urea- $\beta$-mercaptoethanol and separated by SDS-PAGE (B), were either stained by Coomassie blue (lane 0) or electroblotted onto nitrocellulose membranes. Immunoblotting analysis was performed with an $R A$ serum (lane 1) and with the same serum previously immunoadsorbed either onto unblotted control membranes (lane 2), or onto membranes blotted with SC cytokeratins (lane 3) or with low-salt-soluble antigens (lane 4). 


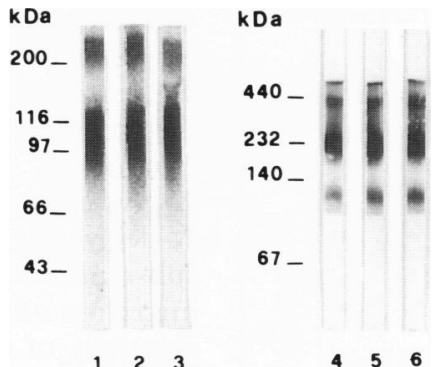

Figure 3 Immunoblotting analysis of low salt epithelial extract after treatment by denaturing or reducing agents, or both. Low salt epithelial extract was precipitated with ethanol and analysed either by SDS-PAGE (lanes 1-3) or by native-PAGE (lanes 4-6). The extract was solubilised in SDS sample buffer without $\beta$-mercaptoethanol (lane 1 ) or with $1 \%$ (lane 2) or $20 \%$ (lane 3) $\beta$-mercaptoethanol. For native-PAGE, the extract was solubilised in water (lane 4), in $8 M$ urea (lane 5) or in $8 M$ urea plus $1 \%$ $\beta$-mercaptoethanol (lane 6). After electroblotting onto nitrocellulose, immunodetection was performed with an $R A$ serum.

PHYSICOCHEMICAL CHARACTERISATION OF THE SC ANTIGENS

To determine the physicochemical characteristics of the antigens we used various conditions of sample solubilisation and of electrophoresis (figs 3 and 4). No effects on the SDS-PAGE pattern were detected when $\beta$-mercaptoethanol was omitted or added at concentrations of $1 \%$ or $20 \%$. In the same way, sample treatment with $8 \mathrm{M}$ urea and with or without $\beta$-mercaptoethanol did not affect the native-PAGE mobility of any of the three antigens (fig 3).

Further physicochemical characterisation of the antigens was carried out using various types of two dimensional electrophoresis (fig 4). Two dimensional IEF/SDS-PAGE allowed three antigenic molecules showing large isoelectric point heterogeneity to be separated. The previously identified 210 kilodalton antigen and a 120-90 kilodalton antigen showed similarly dispersed isoelectric points, generally ranging from 6 to $7 \cdot 2$ and even from $5 \cdot 8$ to 8.5 when detected with high titred serum samples. A third, comma shaped, antigenic molecule with discontinuous isoelectric points ranging from 4.5 to 7.2 and an apparent molecular mass ranging from 130 to 60 kilodaltons was also identified.
Two dimensional IEF/native-PAGE was used to determine the isoelectric characteristics of the three antigens identified by one dimensional native-PAGE. The molecules with the higher molecular masses, referred to as the $A$ and $B$ antigens, showed isoelectric points ranging roughly from 6 to $7 \cdot 2$ (5.8 to 8.5 with high titred serum samples, like the 210 and the 120-90 kilodalton antigens separated by IEF/ PAGE-SDS). The $\mathrm{C}$ antigen had the same isoelectric point distribution as the $130-60$ kilodalton comma shaped antigen.

Lastly, two dimensional electrophoresis combining native-PAGE and SDS-PAGE was used to confirm the relations between the antigens defined by native-PAGE and by IEF/ PAGE-SDS. The A, B, and C antigens were identified as the 210 , the $120-90$, and the 130-60 kilodalton antigens respectively. Their large heterogeneity both in apparent molecular mass and in isoelectric point made purification of the $\mathrm{A}, \mathrm{B}$, and $\mathrm{C}$ antigens somewhat difficult. Gel filtration, anionic exchange, and hydrophobic interaction, used either alone or sequentially, did not allow a complete purification of the molecules (data not shown) During hydrophobic interaction chromatography (fig 5), however, the antigens were sequentially eluted: the $\mathrm{C}$ antigen was identified in early fractions, while decreasing salt concentrations induced the desorption of the $B$ and $A$ antigens, which were identified in later fractions. This showed the lower hydrophobicity of the $\mathrm{C}$ antigen compared with the $A$ and $B$ antigens, which were similar to each other.

BIOCHEMICAL CHARACTERISATION OF THE SC ANTIGENS (fig 6)

Several enzymatic and chemical treatments were performed for the biochemical characterisation of the antigenic components and to determine the biochemical nature of the epitope(s) recognised by the antibodies to SC.

Treatment of low salt extracts with proteinase $\mathrm{K}$ resulted in a complete loss of immunoblotting reactivity with the RA serum samples, demonstrating the involvement of protein moieties in the formation of the three
A

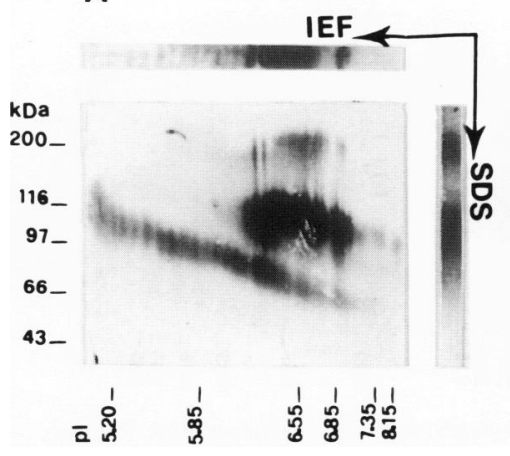

B

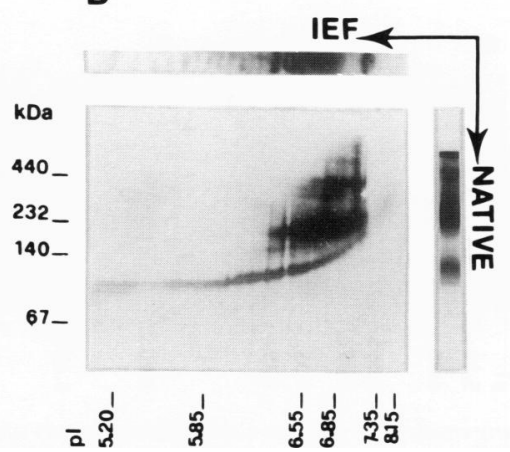

C

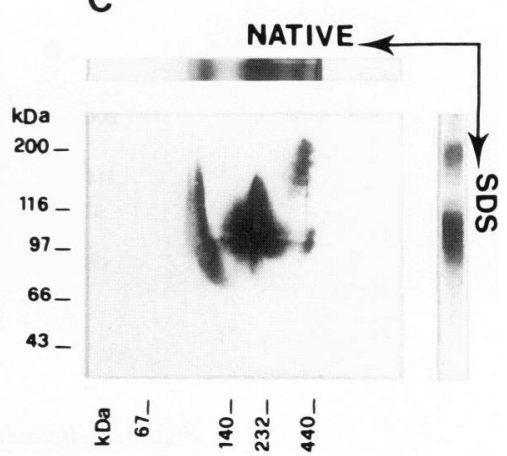

Figure 4 Immunoblotting analysis of low salt epithelial extract using various two dimensional electrophoresis systems. Low salt epithelial extract was solublised in water after ethanol precipitation and analysed either by 5-8 isoelectrofocusing $(A, B)$ or by 8-25\% native-PAGE (C), in the first dimension. The lanes of the first dimension gels were cut and either electrotransferred or equilibrated in the adequate buffer (see 'Materials and methods') for electrophoresis in the second dimension-namely, 7.5\% SDS-PAGE $(A, C)$ or 8-25\% native-PAGE (B). After electroblotting, nitrocellulose sheets were incubated with $R A$ serum samples. 


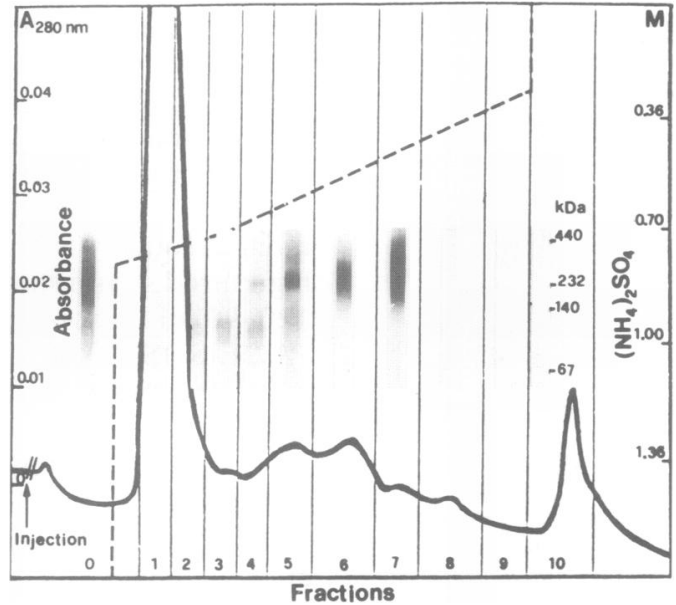

Figure 5 Immunoblotting analysis of the hydrophobic interaction chromatography fractions of the low-salt-soluble antigens previously purified by gel filtration chromatography. Gel filtration of the low salt extract was performed as described in 'Materials and methods'. The eluted fractions containing the antigens were pooled and injected into a phenyl-superose column $(5 \times 0.5 \mathrm{~cm})$ previously equilibrated in $50 \mathrm{mM}$ sodium phosphate, $\mathrm{pH} 7 \cdot 2$, containing $1.7 \mathrm{M}$ ammonium sulphate. Elution was performed at $0.5 \mathrm{ml} / \mathrm{min}$, by decreasing ammonium sulphate concentration (-- ) and absorbance was monitored at $280 \mathrm{~nm}(-)$. The lowsalt-soluble extract (lane 0) and the phenyl-superose fractions (lanes 1-10) were concentrated by precipitation with trichloroacetic acid, solubilised in water, separated by 8-25\% native-PAGE, and analysed by immunoblotting with an $R A$ serum.

antigenic molecules. The marked isoelectric and molecular mass heterogeneity of the three antigens suggested the existence of extensive substitutions, such as glycosylation or phosphorylation of the proteins. Deglycosylation of the antigenic proteins was attempted by various methods classically used to remove the most common carbohydrate moieties. ${ }^{30} 313536$ Whatever the conditions of treatment with sodium hydroxide, used for the $\beta$ elimination of $O$-linked sugars, no modifications of the electrophoretic pattern were obtained before degradation of the peptide chains as seen by Coomassie blue staining. Treatment by $N$-glycanase, despite its broad specificity for $N$-deglycosylation, did not produce any substantial modifications of the electrophoretic migration of the antigens, and the intensity of reactivity of the RA serum samples remained unchanged.

The charge heterogeneity of the antigens might be due to a variable quantity of terminally linked sialic acid residues. This hypothesis was explored using Vibrio cholerae neuraminidase, which hydrolyses terminal $N$ and $O$-acylneuraminic acids. This enzymatic treatment did not modify either the migration of the antigens or the reactivity of the serum samples. Varying degrees of phosphorylation of amino acids might also account for the charge heterogeneity. Calf intestine alkaline phosphatase, used under conditions that induced an almost complete dephosphorylation of the phosphoprotein phosvitin, induced no modifications in either the migration or the immunoreactivity of the treated antigens.

\section{Discussion}

Since Young et $a l,{ }^{10}$ nine different groups have used IIF to study the serum IgG antibodies labelling the SC of rat oesophagus epithelium in large series of patients with rheumatic diseases and have confirmed their high diagnostic specificity for RA (review in 18). ${ }^{11-162022} 24$ This study provides the first isolation and detailed characterisation of the rat oesophagus epithelium antigens targeted by these antibodies. The highly significant
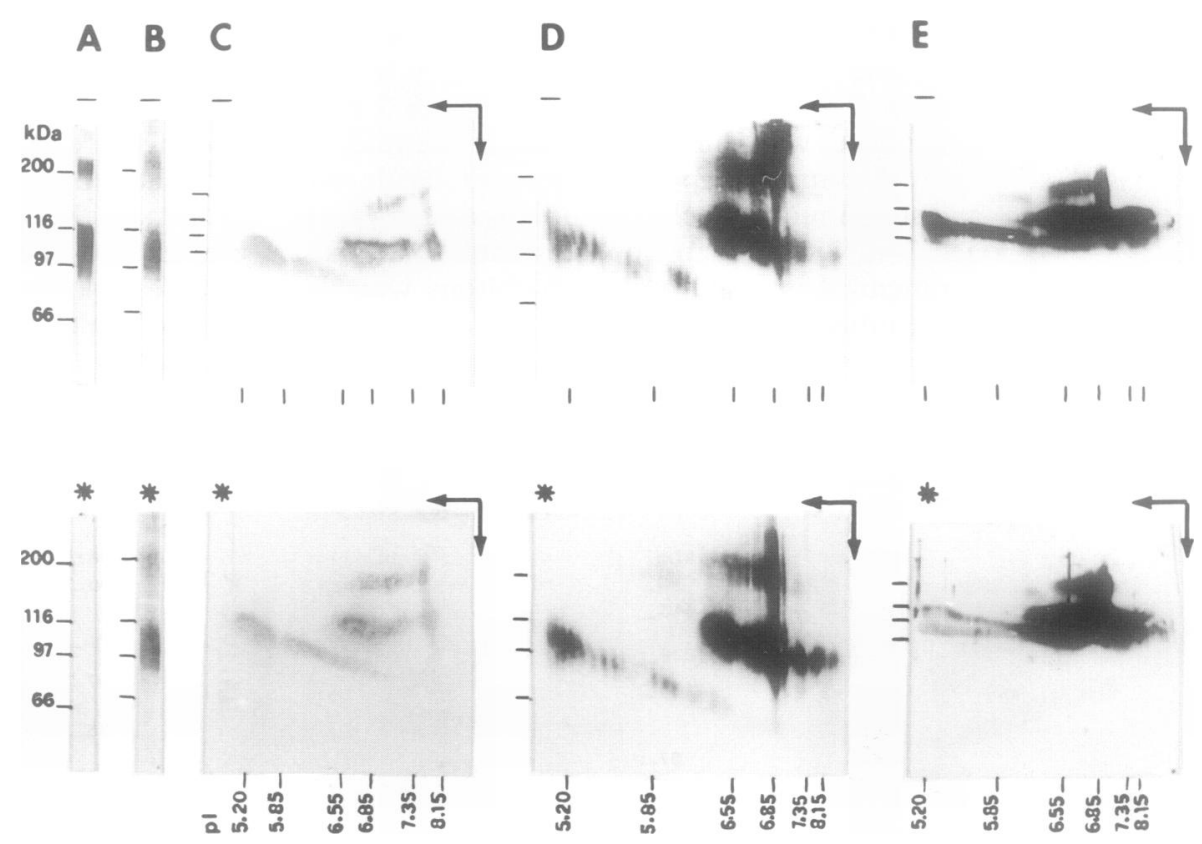

Figure 6 Immunoblotting analysis of the low-salt-soluble antigens after enzymatic and chemical treatments. Various enzymatic or chemical treatments, including proteinase $K(A)$ or $N$-glycanase $(B)$ digestions, mild alkaline $\beta$-elimination $(C)$, and neuraminidase (D) or alkaline phosphatase (E) digestion, were applied to the low salt extract of rat oesophagus epithelia. Treated samples $\left(^{*}\right)$ and untreated samples (-) were separated by one dimensional $7 \cdot 5 \%$ SDS-PAGE $(A, B)$ or two dimensional IEF/SDS-PAGE (that is, 3-9 (C) or 5-8 (D, E) IEF followed by 7.5\% (D) or 8-25\% (C, E) $S D S-P A G E)$ then simultaneously analysed by immunoblotting using $R A$ serum samples. In the sample treated with alkaline phosphatase, serum reactivity to the enzyme produced additional staining. 
correlation we found in RA serum samples between the titre-like value of antibodies to SC determined by IIF and the immunoblotting reactivity to the low-salt-soluble rat oesophagus epithelial antigens clearly shows that the IgG detected by the two methods are largely the same antibodies.

By immunoblotting analyses we found, in the low salt extracts of rat oesophagus epithelium, three different antigenic molecules referred to as $A, B$, and $C$ antigens, separable by two dimensional electrophoresis and identified as proteins by their susceptibility to proteinase $\mathrm{K}$. The absence of modification of the electrophoretic patterns of the antigens after denaturing and reducing treatments showed that the three proteins are not constituted by natural or artefactual associations (neither disulphide nor weak bonds) between each other and confirmed that the antigenic system is actually composed of three distinct proteins. The $\mathrm{A}$ and B proteins appear to be strikingly related, however. Firstly, they share physicochemical properties such as isoelectric point distribution and hydrophobicity and, secondly, their immunoreactivity with RA serum samples was found to be closely related. This latter point was statistically confirmed as the staining intensities of the two molecules, analysed with a large panel of RA serum samples, were found to be highly significantly correlated (GomèsDaudrix V, Sebbag M, et al, in preparation). These physicochemical and immunological analogies might be explained by a precursorproduct relation between the two proteins, the A protein being cleaved to generate the $B$ protein. In contrast, the $C$ protein did not seem to be recognised by all the antibodies which target the $A$ and $B$ proteins. As above, on a large series, its immunoreactivity was also significantly correlated to that of the two other proteins but slightly less so (Gomès-Daudrix $\mathrm{V}$, Sebbag $\mathrm{M}$, et al, in preparation). Nevertheless, these correlations indicate that the existence of epitopes shared by the A, B, and $\mathrm{C}$ proteins is highly probable.

To explain both the extensive charge heterogeneity and the poor resolution of the antigens after SDS-PAGE the existence of posttranslational modifications of the protein moieties was investigated. Protein glycosylation has been frequently shown to have a microheterogeneous character ${ }^{37} 38$ and charged sugar residues, such as sialic acids or sulphated monosaccharides, could modify the net charge of the protein bearing them..$^{39} 40$ Thus classical and widely used enzymatic and chemical methods ${ }^{30313536}$ were chosen to demonstrate glycosylation of the antigens. The immunoblotting analysis of samples treated by the various methods used never showed any significant change in the electrophoretic pattern of the $\mathrm{A}, \mathrm{B}$, or $\mathrm{C}$ antigens. The results suggest that the targeted substituting groups-that is, the best characterised types of asparagine linked glycoconjugates and the 'mucin-type' $O$-linked saccharides-are not the major groups involved in post-translational modifications of the antigens. In the same way the absence of susceptibility to neuraminidase leads to the conclusion that $\alpha-2-3, \alpha-2-6$, or $\alpha-2-8$ linked $N$-acetyl or $N$-glycosyl neuraminic acids are not extensively represented in the antigens. As varying degrees of phosphorylation might also be a source of charge heterogeneity $^{2841}$ we attempted to dephosphorylate the antigens. The absence of effect produced on the antigens shows that phosphorylation is probably not responsible for charge heterogeneity. Taken together, these results suggest that the molecular mass and isoelectric heterogeneity have to be explained in other ways, such as uncommon glycosylation, other classes of sialic acids, ${ }^{40}$ phosphate groups with molecular environments different from those of the control phosphoprotein we used, or even other types of modification.

The persistence of protein antigenicity after all the treatments targeting the sugar moieties shows that these sugars are not the major antigenic determinants. Moreover, periodate oxidation of blotted antigenic proteins did not modify their reactivity with RA serum samples (data not shown), indicating that sugar residues with vicinal groups, such as hydroxyl or mono- or disubstituted amines, are not involved in epitope formation. Together with the protein nature of the $\mathrm{A}, \mathrm{B}$, and $\mathrm{C}$ antigens, and our previous demonstration of predominant distribution in the IgG1 subclass of the antibodies to $\mathrm{SC},{ }^{42}$ which was an indirect argument for recognised determinants being proteins, the results make the peptidic nature of the major epitopes highly probable.

Until now, the antibodies to SC which label the rat oesophagus epithelium have been called 'antikeratin' antibodies, probably in reference to the term 'keratin layer' formerly used for the SC and because cytokeratins are the most abundant proteins in this layer. It was shown, however, that labelling of the rat oesophagus SC by an RA serum was not abolished either by a preadsorption of the serum with lyophilised human epidermal cytokeratins or by the prefixation of an antiserum to human epidermal cytokeratins on rat oesophagus cryosections. ${ }^{22}$ Moreover, we recently showed, by various immunochemical methods, such as enzyme linked immunosorbent assay (ELISA) and immunoblotting, on large series of RA serum samples, that the antibodies to SC are not directed to human epidermal cytokeratins ${ }^{17} 19$ (Simon M, Vincent C, et al, unpublished data). The molecular masses, the isoelectric points, and the high solubility of the A, B, and C antigens are clearly different from those of rat oesophagus epithelium cytokeratins. ${ }^{43}$ The unmodified reactivity of RA serum samples to the $A, B$, and $C$ antigens after adsorption on the SC cytokeratins extracted from the same tissue clearly indicated that the major epitope(s) recognised on the antigenic proteins are not present on the SC cytokeratins, at least in the form and the conformational state they present on nitrocellulose sheets. Considered as a whole, these results show that the $\mathrm{A}, \mathrm{B}$, and $\mathrm{C}$ rat oesophagus epithelium proteins recognised by RA serum samples are not cytokeratins, and that the recognised epitope(s) are absent from these molecules in our experimental conditions. 
The IIF labelling by RA serum samples of the cornified layer of the rat oesophagus epithelium indicates that the recognised proteins correspond to molecules whose synthesis or processing generates epitopes during the late stages of keratinocyte differentiation. The physicochemical and biochemical characteristics of the $\mathrm{A}, \mathrm{B}$, and $\mathrm{C}$ antigens differ from those of all the previously described late differentiation proteins of rat squamous epithelia. We recently identified in human epidermis, however, the targets of the autoantibodies to SC to the basic filaggrin and to a neutral to acidic variant of this protein. ${ }^{44}$ Filaggrin is an intermediate filament aggregating, histidine rich protein which has been characterised in the epidermis of a variety of species, including murine animals and humans. ${ }^{45}$ In rat epidermis its synthesis occurs in the keratinocytes of the granular layer as a heavily phosphorylated 600 kilodalton precursor (profilaggrin), which accumulates in the cytoplasmic keratohyalin granules. ${ }^{45}$ This precursor is formed by the tandem repetition of about 20 filaggrin units separated by short linker peptides. ${ }^{46}$ During the transition from the granular layer to the SC the serine residues are dephosphorylated and profilaggrin is proteolytically cleaved to produce the basic 45 kilodalton filaggrin with heterogeneous isoelectric points ranging from 9 to $10 .^{4748}$

When we applied the various published methods for extraction and purification of epidermal filaggrin to rat oesophagus epithelium $^{48.50}$ we were unable to detect any protein with physicochemical characteristics identical to those of the mature basic form of rat epidermal filaggrin. ${ }^{50 a}$ The absence of this form of filaggrin has also been reported in the rat palate epithelium, another cornified squamous epithelium, whereas immunohistological analyses allowed (pro)filaggrin epitopes to be detected in the keratohyalin granules and in the SC of this epithelium. ${ }^{51}$ Moreover, profilaggrin mRNA was detected in rat oesophagus epithelium by in situ hybridisation..$^{52}$ Therefore, it may be suggested that profilaggrin synthesis actually does occur in rat oesophagus epithelium but that the differentiation pathway in this epithelium differs from that observed in epidermis, and induces specific profilaggrin maturation processes. Therefore, the A, B, and C antigens, immunologically related to human epidermal filaggrin, and different from rat epidermal filaggrin and profilaggrin, might correspond to forms of (pro)filaggrin specific for the rat oesophagus epithelium.

In conclusion, we characterised the proteins targeted by the antibodies to SC, so-called 'antikeratin' antibodies, which have been found to be highly specific for RA and to be related to its most severe and active forms, ${ }^{18}$ to be present at its early stages, ${ }^{20}$ and even to precede its clinical onset. ${ }^{21}$ Identification of the epitope(s) defined by these antibodies on the three rat oesophagus antigens and the search for these epitopes on molecules of the human synovial membrane may provide new insights into the pathogenesis of RA.
We thank Professors A Fournié and B Fournié (Service de Clinique Rhumatologique, CHU Purpan, Toulouse) for providing serum samples from their patients, Professor F Amalric Toulouse) for giving valuable advice, and D Coriat and D Fabé for typing the manuscript.

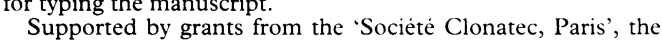
Supported by grants from the 'Societe Clonatec, Paris', the
'Conseil Régional de Midi-Pyrenees', the 'Association pour la 'Conseil Régional de Midi-Pyrenees', the 'Association pour la Recherche sur la Polyarthrite', and the 'Fondation pour la doctoral fellowship awards from the 'Société Clonatec'.

1 Waaler E. On the occurrence of a factor in human serum activating specific agglutination of sheep blood corpuscles. Acta Pathol Microbiol Scand 1940; 17 $172-88$.

2 Wolfe F, Cathey M A, Roberts F K. The latex test revisited. Rheumatoid factor testing in 8,287 rheumatic diseases patients. Arthritis Rheum 1991; 34: 951-60.

3 Hassfeld W, Steiner G, Hartmuth K et al. Demonstration of a new antinuclear antibody (anti-RA33) that is highly specific for rheumatoid arthritis. Arthritis Rheum 1989; 32: 1515-20.

4 Tuaillon $N$, Muller $S$, Pasquali J-L, Bordigoni P, Youinou P, Van Regenmortel M H V. Antibodies from patients with rheumatoid arthritis and juvenile chronic patients with rheumatoid arthritis and juvenile chronic
arthritis analysed with core histone synthetic peptides. Int Arthritis analysed with core histone synthetic pept

Arch Allergy Appl Immunol 1990; 91: 297-305.
5 Nienhuis R L F, Mandema E, Smids C. A new serum factor in patients with rheumatoid arthritis the antiperinuclea factor. Ann Rheum Dis 1964; 23: 302-5.

6 Hoet R M A, Boerbooms A M Th, Arends M, Ruiter D J Van Venrooij W J. Antiperinuclear factor, a marker autoantibody for rheumatoid arthritis: colocalisation of the perinuclear factor and profilaggrin. Amn Rheum Dis 1991 50: 611-8.

7 Menzel J, Steffen C, Kolarz G, Eberl R, Frank O, Thumb N. Demonstration of antibodies to collagen and of collagen-anticollagen immune complexes in rheumatoid arthritis. Ann Rheum Dis 1976; 35: in rheur 50 .

8 Ferriss J, Cooper S, Roessner K, Hochberg M. Antibodies to denatured type II collagen in rheumatoid arthritis: negative association with IgM rheumatoid factor f Rheumatol 1990; 17: 880-4.

9 Terato K, Shimozuru Y, Katayama K, et al. Specificity of antibodies to type II collagen in rheumatoid arthritis Arthritis Rheum 1990; 33: 1493-500.

10 Young B J J, Mallya R K, Leslie R D G, Clark C J M, Hamblin T J. Antikeratin antibodies in rheumatoid arthritis. BMF 1979; ii: 97-9.

11 Johnson G D, Carvalho A, Holborow E J, Goddard D H, Russell G. Antiperinuclear factor and keratin antibodies in rheumatoid arthritis. Ann Rheum Dis 1981; 40. 263-6.

12 Ordeig J, Guardia J. Diagnostic value of antikeratin antibodies in rheumatoid arthritis. $\mathcal{F}$ Rheumatol 1984; 11 : $602-4$.

13 Hajiroussou V J, Skingle J, Gillett A P, Webley M Significance of antikeratin antibodies in rheumatoid arthritis. F Rheumatol 1985; 12 : 57-9.

14 Youinou P, Le Goff P, Colaco C B, et al. Antikeratin antibodies in serum and synovial fluid show specificity fo rheumatoid arthritis in a study of connective tissu diseases. Ann Rheum Dis 1985; 44: 450-4.

15 Meyer O, Fabregas D, Cyna L, Ryckewaert A. Les anticorps anti-kératine. Un marqueur des polyarthrites rhumatö̈de évolutives. Rev Rhum Mal Osteoartic 1986; 53: 601-5.

16 Kirstein H, Mathiesen F K. Antikeratin antibodies in rheumatoid arthritis. Methods and clinical significance. Scand $\mathcal{F}$ Rheumatol 1987; 16: 331-7.

17 Serre G, Vincent C, Fournié B, Lapeyre F, Soleilhavoup J-P, Fournié A. Anticorps anti-stratum corneum d'oesophage de rat, auto-anticorps anti-kératines et anti-épiderme dans la polyarthrite rhumatoïde et différentes affections dans la polyarthrite rhumatoide et differentes affections rhumatologiques. Intérêt diagnostique, aspects fon
mentaux. Rev Rhum Mal Osteoartic 1986; 53: 607-14.

18 Vincent $C$, Serre G, Lapeyre F, et al. High diagnostic value in rheumatoid arthritis of antibodies to the stratum corneum of rat oesophagus epithelium, so-calle 'antikeratin antibodies'. Ann Rheum Dis 1989; 48: $712-22$.

19 Vincent C, Serre G, Fournié B, Fournié A, Soleilhavoup J-P. Natural IgG to epidermal cytokeratin vs IgG to the stratum corneum of the rat oesophagus epithelium, so-called 'antikeratin antibodies', in rheumatoid arthritis and other rheumatic diseases. f Autoimmun 1991; 4: 493-505.

20 Paimela L, Gripenberg $M$, Kurki P, Leirisalo-Repo $M$ Antikeratin antibodies: diagnostic and prognostic markers for early rheumatoid arthritis. Ann Rheum Dis 1992; 51: 743-6.

21 Kurki P, Aho K, Palosuo T, Heliövaara M. Immunopathology of rheumatoid arthritis. Antikeratin antibodies precede the clinical disease. Arthritis Rheum 1992; 35: precede

22 Quismorio F $\mathrm{P}$ Jr, Kaufman $\mathrm{R}$ L, Beardmore $\mathrm{T}$, Mongan E S. Reactivity of serum antibodies to the keratin Mongan E S. Reactivity of serum antibodies to the keratin
layer of rat esophagus in patients with rheumatoid layer of rat esophagus in patients with

23 Kirstein H, Hjarvard K, Mork Hansen T. Antikeratin antibodies in synovial fluid in rheumatoid arthritis. APMIS 1989; 97: 185-9. 
24 Scott D L, Delamere J P, Jones L J, Walton $\mathrm{K}$ W. Significance of laminar antikeratin antibodies to rat oesophagus in rheumatoid arthritis. Ann Rheum Dis 1981; 40: $267-71$.

25 Serre G, Vincent C, Viraben $R$, Soleilhavoup J-P Natural IgM and IgG autoantibodies to epidermal keratins in normal human sera. I: Elisa titration, immunofluorescence study. $\mathcal{F}$ Invest Dermatol 1987; 88: 21-7.

26 Veale R B, Thornley A L, Scott E, Antoni A, Segal I Quantitation of antibodies to cytokeratins in sera from patients with squamous cell carcinoma of the oesophagus. Brf Cancer 1988; 58: 767-72.

27 Arnett F C, Edworthy S M, Bloch D A, et al. The American Rheumatism Association 1987 revised criteria for the classification of rheumatoid arthritis. Arthritis Rheum 1988; 31: 315-24.

28 Sun T T, Green H. Keratin filaments of cultured human epidermal cells. $\mathcal{F}$ Biol Chem 1978; 253: 2053-60.

29 Towbin H, Staehlin T, Gordon J. Electrophoretic transfer of proteins from polyacrylamide gels to nitrocellulose of proteins from polyacrylamide gels to nitrocellulose sheets: procedure and some

30 Adolf G R, Kalsner I, Ahorn H, Maurer-Fogy I, Cantell K Natural human interferon- $\alpha 2$ is O-glycosylated. Biochem f 1991; 276: 511-8.

31 Tarentino A L, Trimble R B, Plummer T H Jr. Enzymatic approaches for studying the structure, synthesis, and processing of glycoproteins. Methods Cell Biol 1989; 32 111-39.

32 Yoshima $\mathrm{H}$, Matsumoto A, Mizuochi $\mathrm{T}$, Kawasaki $\mathrm{T}$, Kobata A. Comparative study of the carbohydrate moieties of rat and human plasma $\alpha 1$-acid glycoproteins. f Biol Chem 1981; 256: 8476-84.

33 Harada M, Hiraoka B Y, Fukasawa K, Fukasawa K M. Phosphoprotein phosphatase activity of bovine intestinal Phosphoprotein phosphatase activity of bovine in

34 Cutting J A, Roth T F. Staining of phosphoproteins on acrylamide gel electrophoregrams. Anal Biochem 1973; 54: 386-94.

35 Florman H M, Wassarman P M. O-linked oligosaccharides of mouse egg ZP3 account for its sperm receptor activity. Cell 1985; 41: 313-24.

36 Spiro R G. Study of the carbohydrates of glycoproteins. Methods Enzymol 1972; 28: 3-43.

37 Berger E G, Bruddecke E, Kamerling J P, Kobata A, Paulson J C, Vliegenthart J F G. Structure, biosynthesis and functions of glycoproteins glycans. Experientia 1982; 38: $1129-62$.

38 Huang C C, Mayer H E Jr, Montgomery R. Microheterogeneity and paucidispersity of glycoproteins. Part I. The carbohydrate of chicken ovalbumin. Carbohydr Res 1970; 13: $127-37$.
39 Yonekura H, Oguri K, Itoh K, et al. Sulfated glycoprotein synthesized by the corneal epithelium of chick embryo having the same molecular weights as cytokeratin having the same molecular weights as

polypeptides. F Biochem 1988; 104: $648-57$.
40 Schauer R. Sialic acids and their role as biological masks. Trends in Biochemical Sciences 1985; 10: 357-60.

41 Righetti P G. General experimental aspects. In: Work T S, Burdon R H, eds. Isoelectric focusing: theory, methodology and application. Amsterdam: Elsevier, 1983: 268-313.

42 Vincent C, Serre G, Basile J-P, et al. Subclass distribution of IgG antibodies to the rat oesophagus stratum corneum (so-called antikeratin antibodies) in rheumatoid arthritis. Clin Exp Immunol 1990; 81: 83-9.

43 Franke W W, Schiller D L, Moll R, et al. Diversity of cytokeratins. Differentiation specific expression of cytokeratin polypeptides in epithelial cells and tissues. 7 Mol Biol 1981; 153: 933-59.

44 Simon M, Girbal E, Sebbag M, et al. The cytokeratin filament-aggregating protein filaggrin is the target of the so-called 'antikeratin antibodies', autoantibodies specific for rheumatoid arthritis. $\mathcal{F}$ Clin Invest. In press.

45 Dale B A, Resing K A, Haydock P V. Filaggrins. In: Goldman R D, Steinert P M, eds. Cellular and molecular biology of intermediate filaments. New York and London Plenum Press, 1990: 393-412.

46 Haydock P V, Dale B A. Filaggrins, an intermediate filament-associated protein: structural and functional implications from the sequence of a cDNA from rat. $D N A$ Cell Biol 1990; 9: 251-61.

47 Harding C R, Scott I R. Histidine-rich proteins (filaggrins): structural and functional heterogeneity during epidermal differentiation. $7 \mathrm{Mol}$ Biol 1983; 170: 651-73.

48 Dale B A. Purification and characterization of a basic protein from the stratum corneum of mammalian epidermis. Biochim Biophys Acta 1977; 91: 193-204.

49 Ball R D, Walker G K, Bernstein I A. Histidine-rich proteins as molecular markers of epidermal differentiation. $\mathcal{F} \mathrm{Biol}$ Chem 1978; 253: 5861-8.

50 Murozuka T, Fukuyama K, Epstein W L. Immunochemical comparison of histidine-rich protein in keratohyalin granules and cornified cells. Biochim Biophys Acta 1979, 579: 334-45.

50a Girbal E, Sebbag M, Gomès-Daudrix V, Croute F, Serre G. Expression of (pro)filaggrin in non-epiderma cornified squamous epithelia: new molecular forms defined in rat oesophagus by human autoantibodies [abstract]. F Invest Dermatol. In press.

51 Dale B A, Lonsdale-Eccles J D, Lynley A M. Two dimensional analysis of proteins of rat oral epithelia and epidermis. Arch Oral Biol 1982; 27: 529-33.

52 Haydock P V, Dale B A. The repetitive structure of the profilagerin profilaggrin gene as demonstrated using epiderma
profilaggrin cDNA. $\mathcal{f}$ Biol Chem 1986; 261: 12520-5. 